\title{
Has common sense prevailed?
}

\author{
Stephen Hancocks OBE \\ Editor-in-Chief
}

The BDJ Upfront section includes editorials, letters, news, book reviews and interviews. Please direct your correspondence to the News Editor,

Adrian O'Dowd at BDJNews@nature.com. Press releases or articles may be edited, and should include a colour photograph if possible.

$\mathrm{I}$ nfective endocarditis (IE), always a serious concern in the dental world, has been the subject of recent, complex controversy in relation to antibiotic prophylaxis (AP), which has now received some clarification from The Scottish Dental Clinical Effectiveness Programme (SDCEP: http://www.sdcep.org.uk).

While guideline committees throughout the world advised dentists to give AP to those at high-risk of IE but to stop giving it to those at moderate-risk, in the UK NICE recommended that dentists stop its use completely. ${ }^{1-3}$ In 2015 an observational study in The Lancet showed that although AP prescribing in England had reduced by $89 \%$ since the NICE guideline change, the incidence of IE had increased significantly. ${ }^{4}$ While this study could not prove a causal relationship the increase in IE was worrying and although NICE performed a review of its guidance they dismissed the results and continued to recommend against the use of AP. Meanwhile, the European Society of Cardiology whose guidelines cover the whole of Europe, performed an in-depth review of the same evidence with a very different outcome. ${ }^{5}$ They concluded the weight of evidence and opinion is now in favour of the efficacy and usefulness of AP in preventing IE in those at high-risk' and that 'the risk of not giving AP outweighed any risk of giving it'.

The difference in the review outcomes caused controversy and concern about the NICE guidance and prompted two Opinion pieces in this Journal, ${ }^{1,2}$ which became the two of the most cited BDJ papers of 2016, and prompted a high level of correspondence. The Opinion pieces and several of the letters made the case that it was inappropriate for NICE to recommend withholding AP from patients at high-risk of IE who might benefit, particularly in light of a change in the law on informed consent. ${ }^{1}$ In June 2016, Sir Andrew Dillon (CEO of NICE) wrote to an MP, who had petitioned NICE on behalf of two women whose husbands had died from IE following hygienist visits for dental scaling, to say that the word 'routinely' had been added to the NICE guidance. ${ }^{2}$ This therefore now read 'Antibiotic prophylaxis against infective endocarditis is not recommended routinely for people undergoing dental procedures'. The change appeared without any notification or publicity to the dental profession and was brought to invasive dental procedures are made aware and provided with advice about methods of prevention including the importance of good oral hygiene and the potential risks and benefits of antibiotic prophylaxis. Additionally, that patients at high-risk of IE (those who SDCEP calls the 'special considerations sub-group') should be given special consideration for AP. It is also pleasing that SDCEP have adopted the advice championed in the $B D J$ and $B M J$ that those at increased

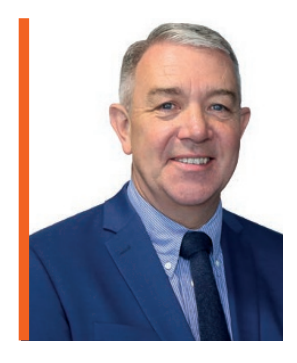

\section{'Those at increased risk of IE undergoing invasive dental procedures should be advised about the symptoms to watch out for...'}

dentists' attention by a $B D J$ article. ${ }^{2}$ As the CEO of NICE wrote in his reply to the MP, 'this amendment should now make clear that in individual cases, antibiotic prophylaxis may be appropriate. ${ }^{2}$

Although welcome, this change caused further confusion since the amended guidelines provided no advice about which individuals should be considered for AP, what dental procedures should be covered or what AP regimen should be used. To help address this, Thornhill and colleagues published articles in the $B D J^{1,2}$ and the $B M J{ }^{6}$ proposing practical advice for clinicians managing patients at risk of IE undergoing invasive dental procedures.

The newly published SDCEP document is therefore very welcome in officially filling this gap with the approval of NICE, British Cardiac Society and the dental Royal Colleges with advice that closely follows that suggested earlier in the Thornhill et al. articles. ${ }^{1,2,6}$ This includes ensuring that those at increased risk of endocarditis undergoing risk of IE undergoing invasive dental procedures should be advised about the signs and symptoms of endocarditis to watch out for, and what to do if they occur, in order to facilitate early diagnosis and treatment, and thereby improve outcomes.

1. Thornhill M H, Dayer M, Lockhart P B et al. Guidelines on prophylaxis to prevent endocarditis. Br Dent J 2016; 220: 51-56.

2. Thornhill M H, Dayer M, Lockhart P B et al. A change in the NICE guidelines on antibiotic prophylaxis. Br Dent J 2016; 221: 112-114.

3. Thornhill MH, Lockhart PB, Prendergast B, Chambers JB Shanson D. NICE and antibiotic prophylaxis to prevent endocarditis. Br Dent J 2015; 218: 619-621.

4. Dayer $\mathrm{M} J$, Jones $\mathrm{S}$, Prendergast $\mathrm{B}$, Baddour $\mathrm{L} \mathrm{M}$, Lockhart P B, Thornhill M H. Incidence of infective endocarditis in England, 2000-13: a secular trend, interrupted time-series analysis. Lancet 2015; 385: 1219-1228.

5. Habib G, Lancellotti P, Antunes M J et al. 2015 ESC Guidelines for the management of infective endocarditis: The Task Force for the Management of Infective Endocarditis of the European Society of Cardiology (ESC) Endorsed by: European Association for Cardio-Thoracic Surgery (EACTS), the European Association of Nuclear Medicine (EANM). Eur Heart J 2015; 36: 3075-3128.

6. Cahill T J, Dayer M, Prendergast B, Thornhill M. Do patients at risk of infective endocarditis need antibiotics before dental procedures? BMJ 2017; 358: j3942.

DOI: $10.1038 /$ sj.bdj.2018.761 